\title{
Editorial
}

\section{Paul Murrell}

In February of 2007 a conference on Directions in Statistical Computing, DSC 2007, was held at the University of Auckland in New Zealand. This conference followed on from previous DSC events held in 1999, 2001, and 2003 at the Vienna University of Technology in Vienna, and in 2005 at the University of Washington in Seattle (http://www.r-project.org/conferences.html).

The focus of the conference was on providing a platform for sharing and discussing ideas about the development of software systems and computing environments for statistical computing. This issue includes 13 papers based on presentations given at DSC 2007.

The majority of talks at DSC 2007 were related to the R project for statistical computing. The articles in this issue include presentations on the core R system, such as Luke Tierney's discussion of code analysis and parallelizing vector operations, Duncan Temple Lang's proposals for making the core R system more extensible, and Peter Dalgaard's suggestions for the improvements to the attach mechanism in $\mathrm{R}$, as well as presentations on extension packages for R, such as John Fox's heplots package, Sandrah Eckel and Roger Peng's stashR package, and Seth Falcon's weaver package.

A common theme to many talks was how to interface $\mathrm{R}$ with other software systems. Hadley Wickham and Michael Lawrence describe the GGobi system for dynamic and interactive graphics and its interface with $\mathrm{R}$ via the rggobi package, Achim Zeileis discusses the integration of $\mathrm{R}$ with the data mining software Weka, Simon Urbanek looks at how to connect code written in $\mathrm{R}$ with code written in Java and Objective $\mathrm{C}$, Duncan Temple Lang describes tools for automating the generation of an $\mathrm{R}$ interface to $\mathrm{C}$ and $\mathrm{C}++$ code, and $\mathrm{E}$. James Harner describes a statistical environment with a

P. Murrell $(\varangle)$

Chair of the DSC 2007 Organizing Committee, Auckland, New Zealand

e-mail: p.murrell@auckland.ac.nz 
front end written in Java and $\mathrm{R}$ as its statistical engine. Finally, Patrick Wessa describes a web-based statistical software service with $\mathrm{R}$ as a back-end.

DSC 2007 was supported by financial contributions from the Department of Statistics at the University of Auckland, the R Foundation for Statistical Computing, the Bioconductor Foundation, the New Zealand Statistical Association, and the National Science Foundation. The general staff of the Department of Statistics also made a large contribution to the smooth running of the conference. 